\title{
CUSTOS DE PRODUÇÃO DE GADO BOVINO EM REGIME DE CONFINAMENTO: ANALISE DO METODO DE CUSTEIO POR ABSORÇÃO EM UMA PROPRIEDADE RURAL EM TANGARA DA SERRA-MT.
}

\author{
Monica Aparecida Burgos Alexandre Pinto ${ }^{1}$ \\ Cleiton Franco ${ }^{2}$
}

\section{RESUMO}

A pecuária de corte é uma importante atividade econômica desenvolvida no Brasil, informações do Ministério da Agricultura dão conta de que a carne bovina, dentre outras carnes produzidas neste país, deverá ter um aumento na produção em 12,6 milhões de toneladas até 2019, isso se deve ao adequado uso das pastagens por meio de técnicas agronômicas modernas e de investimentos em genética, acarretando uma menor utilização de áreas. Este trabalho foi confeccionado com o objetivo de analisar os custos de produção na terminação do gado de corte em regime de confinamento, através do emprego do método de custeio. A metodologia utilizada para a presente pesquisa envolveu estudo de caso de uma propriedade rural, localizada no município de Tangará da Serra-MT. Através de informações coletadas na fazenda, levantou-se o custo do confinamento, bem como a identificação dos elementos que possuem maior influência em relação ao custo de produção na atividade. Foram considerados dois quantitativos de animais confinados, sendo 12.000 animais, durante o ciclo de manejo de 2011 e 11.000 animais, durante o ciclo de manejo de 2012. No resultado da pesquisa verificou-se que os componentes do custo operacional efetivo exerceram maior influência sobre os custos da atividade de confinamento de gado, destacando-se em ordem decrescente: a aquisição de animais, a alimentação. Em relação a essa atividade mostrou-se rentável, tendo como vantagem de destaque o reduzido custo da aquisição boi magro, pois veio de uma filial do grupo, e outro fator foi a alta no preço do período que foi realizado a venda. Conclui-se que a atividade tem condições de se manter em longo prazo se continuar com planejamento adequado.

Palavras-chave: Confinamento. Pecuária de corte. Custos de produção.

\section{INTRODUÇÃO}

A projeção da participação brasileira no comércio internacional vem crescendo a cada ano, com destaque para a produção de carne. Até 2020, a expectativa é que a produção nacional de carne bovina irá suprir a demanda de 44,5\% do mercado mundial. As estimativas indicam que o Brasil pode manter posição de primeiro exportador mundial de carne bovina (PROJEÇÕES DO AGRONEGÓCIO, MAPA).

Conforme Ministério da Agricultura, a bovinocultura é um dos principais destaques do agronegócio brasileiro no cenário mundial. O Brasil é dono do segundo maior rebanho efetivo no mundo, com cerca de 200 milhões de cabeças. Além disso, desde 2004, assumiu a

\footnotetext{
${ }^{1}$ Acadêmico do curso de Ciências Contábeis da UNEMAT - Campus de Tangará da Serra,

e-mail: monica-pinto2011@ @otmail.com

${ }^{2}$ Professor do curso de Ciências Contábeis da UNEMAT - Campus de Tangará da Serra,

e-mail:cleitonfranco@unemat.br 
Custos de produção de gado bovino em regime de confinamento: analise do metodo de custeio por absorção em uma propriedade rural em Tangara da Serra-MT

Monica Aparecida Burgos Alexandre Pinto

Cleiton Franco

liderança nas exportações, com um quinto da carne comercializada internacionalmente e vendas em mais de 180 países. )

Mato Grosso é o estado possuidor do maior rebanho bovino do Brasil de acordo com dados do IBGE apresentando rebanho efetivo de 29.265.718 cabeças. As regiões que merecem destaque são a região norte, nordeste e sudoeste. Segundo dados da Secretaria de Estado de Planejamento (SEPLAN), os principais produtores de carne bovina são os municípios de Cáceres, Juara, Vila Bela da Santíssima Trindade, Pontes e Lacerda, Alta Floresta e Vila Rica.

Em estudo pioneiro, no estado de Mato Grosso, o Instituto Matogrossense de Economia Agropecuária (IMEA) realiza levantamento das intenções de confinamento, visando à identificação do quantitativo do rebanho destinado a esta atividade da pecuária de corte.

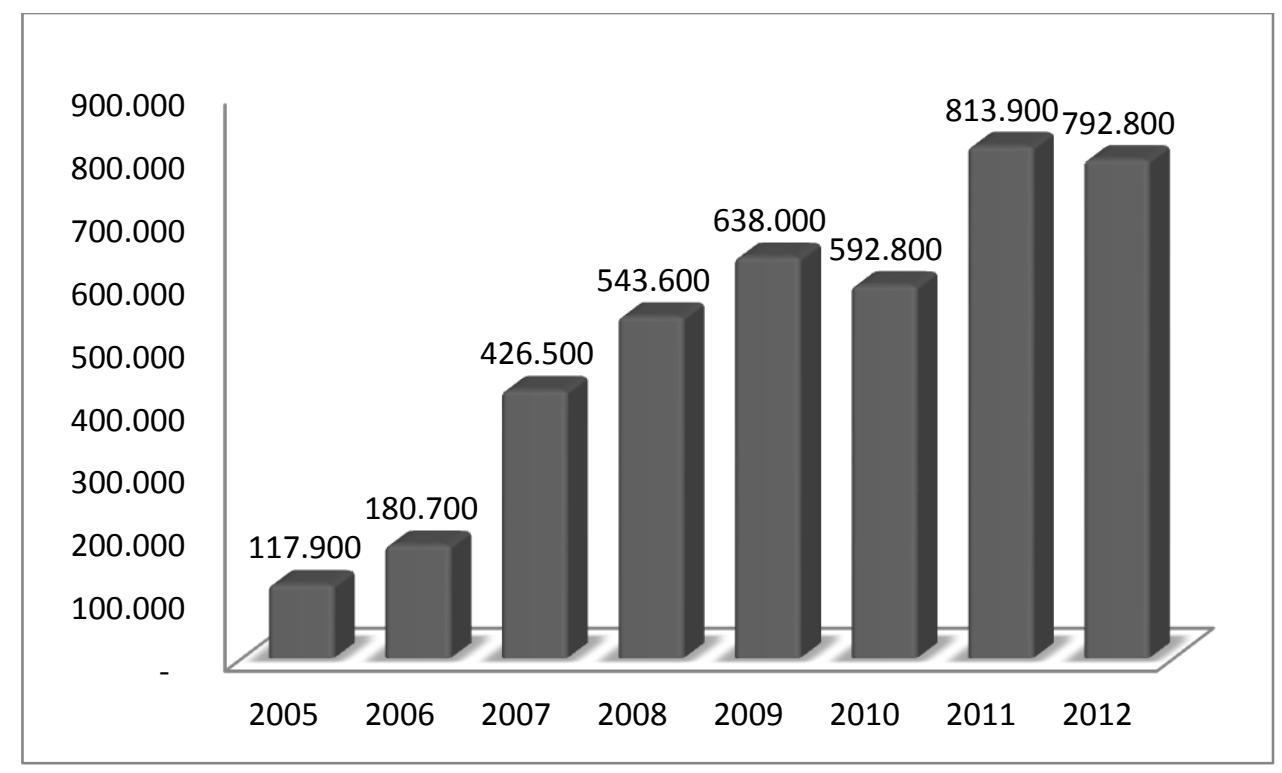

Figura 1: Rebanho de bovinos em regime de confinamento em Mato Grosso

Fonte: IMEA (2013)

$\mathrm{Na}$ figura 1, podemos observar que os primeiros resultados confirmam o crescente aumento nas expectativas de confinamento dos produtores rurais de atividade de pecuária em Mato Grosso. No período de 2005 a 2011 houve aumento nas projeções de intenção de confinamento como nos confinamentos realizados no mesmo período, da ordem de $690 \%$. Porém em 2012, devido a constante redução do preço e aumento dos custos de alimentação e de aquisição de bezerros, os resultados demonstraram uma pequena redução da ordem de $3 \%$, tanto nas intenções como no efetivo de rebanho confinado. Apesar de representar uma fatia 
Custos de produção de gado bovino em regime de confinamento: analise do metodo de custeio por absorção em uma propriedade rural em Tangara da Serra-MT

Monica Aparecida Burgos Alexandre Pinto

Cleiton Franco

mínima do rebanho produzido em Mato Grosso, os números continuam em crescimento, demonstrando que a atividade está em constante expansão.

O primeiro levantamento oficial apresentado pelo Instituto Mato-grossense de Economia Agropecuária (IMEA), para o período de 2013, demonstra que menos de 810 mil sairão do pasto para serem 'confinados'. Estimativas da Associação Nacional dos Confinadores (Assocon) apontam que o confinamento de bovinos no Estado poderia crescer 19,6\%. Este percentual superaria a média nacional e colocaria o Mato Grosso na disputa pelo primeiro lugar em terminação, juntamente com Goiás, estado este que no ano passado confinou mais de 1 milhão de cabeças, maior volume do país. Em Tangará da Serra, localização do estudo de caso em questão, o rebanho apresenta a totalidade de 239.773 cabeças, da raça nelore em sua maior parte. Desse total, 15.000 estão confinados na fazenda objeto deste estudo.

A revisão de literatura perpassa por diferentes áreas de discussão, qual seja: econômica, de análise de custos e de rentabilidade. Dentre os artigos, destacando a abordagem de análise econômica, podemos citar os autores Moreira et al. (2009), Sipp (2011), na discussão acerca da rentabilidade podem ser citados os autores Klein e Staudt (2009) e Lopes e Magalhães (2005) e considerando a análise de custos podem ser citados os trabalhos de Casturino e Sthanghilin (2010), Kubiak (2008), Ziliotto et al. (2010) e da Silva et al. (2008)

Moreira et al. (2009) faz uma análise econômica dos resultados obtidos da terminação de bovinos de corte em confinamento em uma propriedade no município de Cristalina-GO, ocasião em que ele calculou o custo de produção além de fazer a identificação de quais itens teriam maior influência em relação ao custo operacional efetivo. Ainda na mesma linha de pesquisa vem Sipp (2011) que analisou os resultados econômicos no primeiro lote de confinamento em uma propriedade agrícola localizada no município de Bom Sucesso do SulPR, após calcular o custo de produção e a viabilidade econômica da atividade.

$\mathrm{Na}$ análise de rentabilidade temos os autores Klein e Staudt (2009) que fazem o estudo de rentabilidade do confinamento utilizando um método de custeio, através do qual calculouse os custos de produção e em seguida foram identificados os itens que exerceram maior influência sobre o custo operacional efetivo desta atividade em uma fazenda no município de Ribas do Rio Pardo-MS. Na mesma linha de estudo vem os autores Lopes e Magalhães (2005) que analisaram a rentabilidade do confinamento na terminação de bovinos de corte e identificou os itens que mais influenciam os custos finais, em uma propriedade no oeste do estado de Minas Gerais. 
Custos de produção de gado bovino em regime de confinamento: analise do metodo de custeio por absorção em uma propriedade rural em Tangara da Serra-MT

Monica Aparecida Burgos Alexandre Pinto

Cleiton Franco

Trabalhando com análises dos custos temos os autores Casturino e Sthanghilin (2010), que pesquisaram, analisaram e interpretaram as formas de se fazer um efetivo controle de custos utilizado no confinamento de bovinos de corte em uma propriedade no município de Sinop-MT. Na mesma linha de estudo tem o autor Kubiak (2008), que fez uma experiência de aplicação de um sistema de custos que teve como resultado que o gado é responsável por mais de $58,23 \%$ dos custos, seguido dos alimentos que representam 38,70\% dos custos. Podendo também citar Ziliotto et al. (2010) que através de suas pesquisas vieram informar e evidenciar qual dos métodos de produção do gado de corte é possível obter os resultados esperados com menor custo e maior lucro, através de uma analise entre os sistemas de bovinocultura.

Um sistema de custos completo possui objetivos amplos, refletindo a importância da ferramenta para a gestão e administração de qualquer empreendimento agropecuário, onde os intervalos de tempo entre a produção e comercialização, exigindo técnicas especiais para apresentação dos custos e resultados do empreendimento (MARION E SEGATTI, 2010). Os produtores rurais não controlam adequadamente os custos de produção. (FARIA e AGUIAR, 2005); (RESENDE E AGUIAR, 2010). Diante do exposto, surge a problemática acerca da necessidade do desenvolvimento da aplicação de um método de custeio que se adeque a fase da terminação do gado de corte em confinamento dentro de uma propriedade rural.

O objetivo deste trabalho é identificar o processo de formação dos custos de confinamento e analisar a rentabilidade da comercialização de bovinos na fazenda São Pedro, em Tangará da Serra município da região centro-oeste do estado de Mato Grosso. Os objetivos específicos são os de apresentar os conceitos de atividade pecuária e de custos, descrever o processo de produção de engorda em regime de confinamento e mostrar os custos inerentes ao processo produtivo.

\section{REFERENCIAL TEÓRICO}

\subsection{Gestão do agronegócio na atividade pecuária}

A gestão do agronegócio perpassa pela atividade na empresa rural, caracterizada como um empreendimento ou negócio relativo à atividade agropecuária. A atividade agropecuária pode ser subdividida em agrícola e pecuária. A atividade pecuária é conceituada como a arte de desenvolver o gado, este situado no campo, seja para serviços destinados a lavoura, para consumo das famílias rurais ou para fins comerciais e industriais (MARION, 1996).

$\mathrm{Na}$ atividade pecuária, a criação de animais pode ser realizada de forma extensiva, semi-intensiva ou confinamento. No sistema de criação extensiva o animal é criado de forma 
Custos de produção de gado bovino em regime de confinamento: analise do metodo de custeio por absorção em uma propriedade rural em Tangara da Serra-MT

Monica Aparecida Burgos Alexandre Pinto

Cleiton Franco

livre, solto no pasto. No sistema de criação semi-intensiva e confinamento o gado é criado e desenvolvido em pequenos currais de área restrita, mantido exclusivamente para ganho de peso (MARION E SEGATTI, 2010).

Lopes e Magalhães (2005) afirmam que a engorda leva a lotação mais acentuada que os regimes de criação extensiva, porém em confinamento o custo de produção torna-se mais caro. As vantagens seriam a redução da idade de vida do animal, produção de carne com ganho de qualidade, aumento da taxa de desfrute reduzindo a ociosidade dos frigoríficos na entressafra, propiciando ainda maior giro de capital, aproveitamento das áreas de pastagens para outras atividades e elevada produção de adubo orgânico.

\subsection{Conceito de Custos}

Conhecer o custo unitário de cada animal presente em estoque, pertencente a cada lote ou ao total do rebanho em determinado período torna-se informação imprescindível ao gerenciamento da atividade rural. A finalidade não é apenas de apuração da rentabilidade no ato da comercialização, mas para evitar a manutenção do gado na propriedade rural quando os custos tornam-se excessivos em relação ao ganho de peso (MEGLIORINI, 2007; MARION, 2007).

O conceito de custos representa a agregação dos gastos realizados com insumos e/ou bens e serviços aplicados ou consumidos na produção da atividade da firma. Estes podem ser classificados como: Custos fixos, quando decorrem da manutenção da estrutura de produção da firma, independente da quantidade que venha a ser produzida dentro do limite da capacidade instalada, ou custos variáveis podem ser caracterizados como os que aumentam ou diminuem conforme o volume produzido. (WERNKE, 2001; DUTRA, 1995; MEGLIORINI, 2007; RIBEIRO, 2009).

Os gastos podem ainda ser classificados como custos indiretos, apropriados ao produto em função de uma base de rateio ou apropriação, pois participam das fases da produção, não podendo ser alocados diretamente a um produto devendo ser rateados. Por fim, os denominados custos diretos, poderão ser alocados diretamente a um produto uma vez que sua ocorrência esteja associada diretamente àquele produto (WERNKE, 2001; DUTRA, 1995; MEGLIORINI, 2007; RIBEIRO, 2009).

\subsection{Sistemas de custeio}

Os sistemas de custeio tem por finalidade a produção de informações para os usuários da contabilidade, através da identificação, mensuração e classificação de dados. A partir de dados coletados por meio de pesquisa, planejamento e controle das operações ocorre a 
Custos de produção de gado bovino em regime de confinamento: analise do metodo de custeio por absorção em uma propriedade rural em Tangara da Serra-MT

Monica Aparecida Burgos Alexandre Pinto

Cleiton Franco

geração de relatórios contábeis possibilitando aos gestores a adequada tomada de decisão. Os dados podem ser de natureza monetária ou física, tornando a contabilidade de custos ferramenta relevante no processo de gestão. Dentre os diversos sistemas de custeio os principais são: custeio por absorção e custeio direto ou variável. ( MEGLIORINI, 2007; RIBEIRO, 2009).

O sistema de custeio por absorção é o método legalmente aceito no Brasil, pois além de atender os princípios contábeis geralmente aceitos, está de acordo com as leis de tributação e fiscal brasileira. O procedimento para este método consiste na agregação de todos os custos, classificados como diretos e indiretos, participando do processo de produção, desde a elaboração do produto até a sua fase de acabamento. (IUDICIBUS, 2000; HANSEN E MOWEN, 2001; CREPALDI, 2007; MEGLIORINI, 2007).

O sistema de custeio direto ou variável, leva em consideração a apropriação dos custos em fixo e variáveis. Apenas os custos variáveis são relacionados ao produto. Sendo assim, os custos de natureza fixa são considerados como custos do período, sendo considerados como pertencentes diretamente ao resultado do período( IUDICIBUS, 2000; HANSEN E MOWEN, 2001; CREPALDI, 2005; MEGLIORINI, 2007).

\section{METODOLOGIA}

A presente pesquisa caracterizou-se como de natureza exploratória, descritiva; realizada mediante um estudo de caso. A justificativa para o estudo de caso ampara-se na importância da reunião de informações qualitativas e quantitativas, visando à resolução de problemas baseados na avaliação de um único caso estudado (BEUREN, 2006).

A fundamentação teórica foi baseada em pesquisa bibliográfica, que vem contribuir e complementar a pesquisa descritiva realizada através da analise dos dados levantados. A pesquisa bibliográfica por ser de natureza teórica, mediante material já elaborado, principalmente livros e artigos científicos, referenciando o problema a ser investigado (LAKATOS E MARCONI, 1991; BEUREN, 2006).

Após a coleta das informações, analisou-se os dados da empresa em estudo, realizando a elaboração de tabelas, tendo como base as informações levantadas e por meio das fontes de evidências utilizadas.

\subsection{Margem de Contribuição}

A margem de contribuição é igual à receita menos a soma dos custos e despesas variáveis, tendo como função identificar qual produto melhor absorve o custo fixo da empresa 
Custos de produção de gado bovino em regime de confinamento: analise do metodo de custeio por absorção em uma propriedade rural em Tangara da Serra-MT

Monica Aparecida Burgos Alexandre Pinto

Cleiton Franco

e em seguida gerar lucro, afirmam Martins, 1996 e Megliorini, 2007. Que trazem a fórmula para encontrar a margem de contribuição:

$$
\mathrm{MC}=\mathrm{PV}-(\mathbf{C V}+\mathbf{D V})
$$

Onde:
MC: Margem de Contribuição
CV: Custos Variáveis
PV: Preço de Venda
DV: Despesas Variáveis

\subsection{Ponto de Equilíbrio}

Megliorini (2007) diz que é importante conhecer a técnica de calcular o ponto de equilíbrio, que consiste em encontrar o ponto em que a empresa já pagou os custos e despesas porém ainda não tem lucro. Em uma empresa nem todos os produtos terão a mesma margem de contribuição. Para chegar ao ponto de equilíbrio em unidades pode-se utilizar a seguinte fórmula:

$P E=\underline{C+D \text { fixos }}$

\section{Unitária}

Onde:

PE é o ponto de equilíbrio

$\mathrm{C}+\mathrm{D}$ fixos é o custo fixo total do período

MCun é a margem de contribuição per capita

Para encontrar o ponto de equilíbrio em valores usa-se a seguinte fórmula:

$\mathrm{PE} \equiv$ Custos e Despesas Fixos

\section{1 - (Custos e Despesas Variáveis Unitários)}

Preço de Venda unitário

Onde:

CF é o custo fixo total do período

Custos Variáveis unitário do período

Despesas Variáveis unitário do período

\section{DISCUSSÃO E RESULTADOS}

\section{1-Descrição do processo de produção de engorda em regime de confinamento}

A fazenda São Pedro está localizada no município de Tangará da Serra e dispõe de 2.400 hectares de extensão, o que propicia a propriedade ter uma fábrica de ração, silos e barracões para armazenar grãos. 
Custos de produção de gado bovino em regime de confinamento: analise do metodo de custeio por absorção em uma propriedade rural em Tangara da Serra-MT

Monica Aparecida Burgos Alexandre Pinto

Cleiton Franco

A atividade econômica desenvolvida por está fazenda é a pecuária de corte de gado da raça nelore, pois eles são bastante resistentes ao clima desta região e é propícia ao comércio de carne. Também lá é feito um trabalho de melhoramento genético, trazendo vantagens ao seu plantel, haja vista que este procedimento favorece ao boi apresentar maior ganho de peso acarretando em abate precoce.

Conforme orientação dos professores da Universidade de Viçosa, Cecilia de F. Souza, Ilda de F.F. Tinoco e Valmir Sartor, é necessário que a fazenda tenha para dar apoio à produção do gado em regime de confinamento, um setor de produção, deposito de alimentos, silos, além de um sistema de manejo de dejetos que venha a facilitar escoamento das aguas, um escritório, deposito de medicamentos, sanitários, entre outros. Levando em consideração esta recomendações podemos dizer que a fazenda é adequada, pois esta equipada com cinco tratores que são utilizados para fazer a distribuição da ração que é oferecida aos animais nos cochos dos currais de confinamento.

$\mathrm{O}$ boi magro chega à fazenda para o confinamento e permanece em pasto por aproximadamente 10 dias, depois é transferido para os currais. Este procedimento ocorre toda vez que um lote chega à propriedade, evitando o estresse do animal que pode vir a atrasar o ganho de peso. Este processo ocorre uma vez ao ano.

No ano de 2012, foram confinadas 11.000 cabeças, 1.000 a menos, em relação ao período anterior de 2011, quando foram confinadas 12.000 cabeças. A decisão de confinamento perpassa pela expectativa de venda do boi gordo, variando de acordo com a demanda do mercado, sendo outra variável de influencia é o preço do boi gordo e oferta de boi magro. O boi magro é fornecido por uma fazenda do grupo que fica no município de Juruena-MT. Porém quando a filial não supre a necessidade compram-se animais de outros produtores.

O boi magro chega aos currais, com 11@, permanecendo lá por 100 dias. Estes animais tem um ganho diário de $1,5 \mathrm{~kg}$, o que por semana somam $10,5 \mathrm{~kg}$ e por fim $31,5 \mathrm{~kg}$ mensais. Depois deste período já com 18@ são transportados ao frigorifico da região, onde é realizado o abate. Este ganho de peso se dá devido ao alimento que é oferecido das cinco horas da manha ate às quatro horas da tarde, uma ração composta de ração seca (farelo de milho e soja), volumosa e silagem (de capim, bagaço de cana e caroço de algodão), também é oferecida água em cochos que ficam sempre próximo a ração, além do sal mineral.

Normalmente, com a idade de 24 meses, o boi atinge o peso ideal de 18 @, constatado através de pesagem na balança instalada no curral. Esta conferencia é realizada a cada 15 dias até a obtenção do peso ideal. Ainda no curral, são combatidos os carrapatos e verminoses 
Custos de produção de gado bovino em regime de confinamento: analise do metodo de custeio por absorção em uma propriedade rural em Tangara da Serra-MT

Monica Aparecida Burgos Alexandre Pinto

Cleiton Franco

através de medicamento no cocho por meio de homeopatia e pulverização de medicamento nos animais. Após todo processo de confinamento, o gado é comercializado a um frigorífico situado no município de Tangará da Serra. O transporte é realizado pelo comprador.

\subsection{Custos de confinamento}

Através da tabela 1, pode se verificar os custos com o confinamento em uma propriedade rural localizada no município de Tangará da Serra-MT, estes são classificados, pelo critério de custeio por absorção, em diretos e indiretos, ou seja, quais ocorreram ligados diretamente ao confinamento e quais foram ligados indiretamente a fase de engorda. $\mathrm{O}$ valor total de cada conta contábil foi fornecido pelo gerente da fazenda, os quais foram utilizados em novos cálculos a fim de encontrar então a partir desses valores, os custos unitários, por @, lucro na venda do boi gordo e quanto cada custo representa, em percentual, diante do custo total. O custo unitário foi resultante da divisão do valor de cada item pelo numero de cabeças confinadas, assim chegando ao custo por cabeça. Em seguida este resultado foi dividido pela quantidade de arrobas de cada bovino, que de acordo com o padrão da fazenda, deve adquirir antes de ir para o abate, encontrando-se assim o custo por arroba. O lucro foi encontrado após verificar o preço de venda de cada cabeça no período e subtrair o custo unitário. Em seguida, são calculadas as participações em percentuais, encontrando assim o percentual da margem de contribuição que representa cada item em relação ao custo total do confinamento.

Tabela 1 - Custos diretos e indiretos de confinamento na Fazenda São Pedro nos períodos de 2011 e 2012. 
Custos de produção de gado bovino em regime de confinamento: analise do metodo de custeio por absorção em uma propriedade rural em Tangara da Serra-MT

Monica Aparecida Burgos Alexandre Pinto

Cleiton Franco

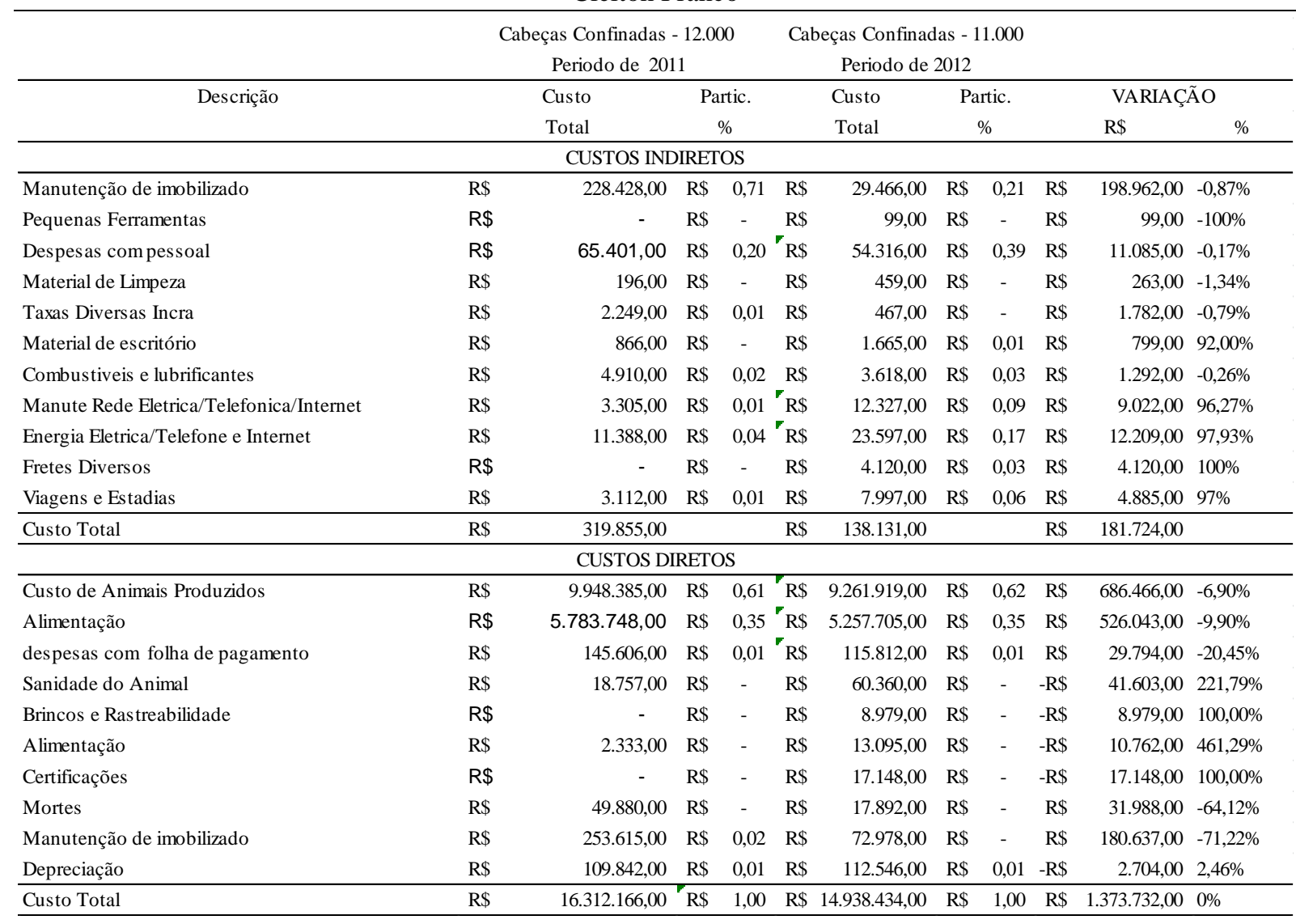

Como pode ser visto na tabela 1, os custos estão classificados em custos diretos representados pelas contas: custo de animais produzidos, alimentação, despesas com folha de pagamento, sanidade animal, brincos e rastreabilidade, alimentação, certificações mortes, manutenção de imobilizado, depreciação e custos indiretos representados pelas contas manutenção do imobilizado, pequenas ferramentas, despesas com pessoal, material de limpeza, taxas diversas do Incra, material de escritório, combustíveis e lubrificantes, manutenção de rede elétrica, internet e telefone, energia elétrica internet e telefone, fretes diversos, viagens e estadias e custo total.

Nos dois períodos analisados podemos destacar como os custos diretos que possuem mais relevância, o custo de animais produzidos que nos dois períodos foi de $\mathrm{R} \$ 800,00$ por cabeça de boi magro, rações em 2011 foi $\mathrm{R} \$ 481,91$ por cabeça e em 2012 foram $\mathrm{R} \$ 477,79$ por cabeça e frete de animais com custo em 2011 foram de $\mathrm{R} \$ 28,81$ e em 2012 foram de $\mathrm{R} \$ 41,98$. Dentre os custos indiretos, mais relevantes são manutenção de instalações e infraestrutura em 2011 foram $\mathrm{R} \$ 17,01$ e em $2012 \mathrm{R} \$ 8,93$; e serviços prestados por terceiros em 2011 foram $\mathrm{R} \$ 3,08$ e em 2012 foram $\mathrm{R} \$ 3,54$.

Tabela 2 - Custos fixos e variáveis de confinamento na Fazenda São Pedro nos períodos de 2011 e 2012. 
Custos de produção de gado bovino em regime de confinamento: analise do metodo de custeio por absorção em uma propriedade rural em Tangara da Serra-MT

Monica Aparecida Burgos Alexandre Pinto

Cleiton Franco

\begin{tabular}{|c|c|c|c|c|c|c|c|c|c|c|c|c|}
\hline \multirow{3}{*}{ Descrição } & \multicolumn{4}{|c|}{$\begin{array}{c}\text { Cabeças Confinadas - } 12.000 \\
\text { Periodo de } 2011\end{array}$} & \multicolumn{5}{|c|}{$\begin{array}{c}\text { Cabeças Confinadas - } 11.000 \\
\text { Periodo de } 2012\end{array}$} & & & \\
\hline & \multirow{2}{*}{\multicolumn{2}{|c|}{$\begin{array}{c}\text { Custo } \\
\text { Total } \\
\end{array}$}} & \multirow{2}{*}{\multicolumn{2}{|c|}{$\begin{array}{c}\text { Partic. } \\
\% \\
\end{array}$}} & \multirow{2}{*}{\multicolumn{2}{|c|}{$\begin{array}{l}\text { Custo } \\
\text { Total } \\
\end{array}$}} & \multirow{2}{*}{\multicolumn{3}{|c|}{$\begin{array}{c}\text { Partic. } \\
\%\end{array}$}} & \multicolumn{3}{|c|}{ VARIAÇÃO } \\
\hline & & & & & & & & & & $\mathrm{R} \$$ & & $\%$ \\
\hline \multicolumn{13}{|c|}{ CUSTOS VARIÁ VEIS } \\
\hline Custo de Animais Produzidos & $\mathrm{R} \$$ & $9.600 .000,00$ & $\mathrm{R} \$$ & 0,61 & $\mathrm{R} \$$ & $8.800 .000,00$ & $\mathrm{R} \$$ & 0,60 & $\mathrm{R} \$$ & $800.000,00$ & $\mathrm{R} \$$ & 0,01 \\
\hline GTA-Transferencia & $\mathrm{R} \$$ & $2.664,00$ & $\mathrm{R} \$$ & - & $\mathrm{R} \$$ & 45,00 & $\mathrm{R} \$$ & - & $\mathrm{R} \$$ & $2.619,00$ & $\mathrm{R} \$$ & - \\
\hline Sal Mineral & $\mathrm{R} \$$ & - & $\mathrm{R} \$$ & - & $\mathrm{R} \$$ & $1.995,00$ & $\mathrm{R} \$$ & - & $\mathrm{R} \$$ & $1.995,00$ & $\mathrm{R} \$$ & - \\
\hline Vermifugos & $\mathrm{R} \$$ & $8.576,00$ & $\mathrm{R} \$$ & - & $\mathrm{R} \$$ & $3.320,00$ & $\mathrm{R} \$$ & - & $\mathrm{R} \$$ & $5.256,00$ & $\mathrm{R} \$$ & - \\
\hline Outros Produtos Veterinarios & $\mathrm{R} \$$ & - & $\mathrm{R} \$$ & - & $\mathrm{R} \$$ & $8.080,00$ & $\mathrm{R} \$$ & - & $\mathrm{R} \$$ & $8.080,00$ & $\mathrm{R} \$$ & - \\
\hline Brincos e Rastreabilidade & $\mathrm{R} \$$ & - & $\mathrm{R} \$$ & - & $\mathrm{R} \$$ & $8.979,00$ & $\mathrm{R} \$$ & - & $\mathrm{R} \$$ & $8.979,00$ & $\mathrm{R} \$$ & - \\
\hline Mortes & $\mathrm{R} \$$ & $49.880,00$ & $\mathrm{R} \$$ & - & $\mathrm{R} \$$ & $17.892,00$ & $\mathrm{R} \$$ & - & $\mathrm{R} \$$ & $31.988,00$ & $\mathrm{R} \$$ & - \\
\hline Vacinas & $\mathrm{R} \$$ & $10.181,00$ & $\mathrm{R} \$$ & - & $\mathrm{R} \$$ & $48.960,00$ & $\mathrm{R} \$$ & - & $\mathrm{R} \$$ & $38.799,00$ & $\mathrm{R} \$$ & - \\
\hline Frete de animais & $\mathrm{R} \$$ & $345.721,00$ & $\mathrm{R} \$$ & 0,02 & $\mathrm{R} \$$ & $461.874,00$ & $\mathrm{R} \$$ & 0,03 & $\mathrm{R} \$$ & $116.153,00$ & $\mathrm{R} \$$ & 0,01 \\
\hline Rações-Confinamento & $\mathrm{R} \$$ & $5.783 .748,00$ & $\mathrm{R} \$$ & 0,37 & $\mathrm{R} \$$ & $5.255 .710,00$ & $\mathrm{R} \$$ & 0,36 & $\mathrm{R} \$$ & $528.038,00$ & $\mathrm{R} \$$ & 0,01 \\
\hline Custo Total & $\mathrm{R} \$$ & $15.800 .770,00$ & & & $\mathrm{R} \$$ & $14.606 .855,00$ & & & & & & \\
\hline \multicolumn{13}{|c|}{ CUSTOS FIXOS } \\
\hline Outros Custos Divs/ Desenv Social & $\mathrm{R} \$$ & $23.881,00$ & $\mathrm{R} \$$ & 0,03 & $\mathrm{R} \$$ & 42,00 & $\mathrm{R} \$$ & 0,00 & $\mathrm{R} \$$ & $23.839,00$ & $\mathrm{R} \$$ & 0,03 \\
\hline Manutenção do imobilizado & $\mathrm{R} \$$ & $514.648,00$ & $\mathrm{R} \$$ & $0,60^{\prime}$ & $R \$$ & $248.023,00$ & $\mathrm{R} \$$ & 0,41 & $\mathrm{R} \$$ & $266.625,00$ & $\mathrm{R} \$$ & 0,19 \\
\hline Despesas compessoal & $\mathrm{R} \$$ & $189.459,00$ & $\mathrm{R} \$$ & $0,222^{\prime}$ & $\mathrm{R} \$$ & $179.459,00$ & $\mathrm{R} \$$ & 0,30 & $\mathrm{R} \$$ & $10.000,00$ & $\mathrm{R} \$$ & 0,08 \\
\hline Material de Limpeza & $\mathrm{R} \$$ & 196,00 & $\mathrm{R} \$$ & 0,00 & $\mathrm{R} \$$ & 459,00 & $\mathrm{R} \$$ & 0,00 & $\mathrm{R} \$$ & 263,00 & $\mathrm{R} \$$ & - \\
\hline Taxas Diversas Incra & $\mathrm{R} \$$ & $2.249,00$ & $\mathrm{R} \$$ & 0,00 & $\mathrm{R} \$$ & 467,00 & $\mathrm{R} \$$ & 0,00 & $\mathrm{R} \$$ & $1.782,00$ & $\mathrm{R} \$$ & - \\
\hline Material de escritório & $\mathrm{R} \$$ & 866,00 & $\mathrm{R} \$$ & 0,00 & $\mathrm{R} \$$ & $1.665,00$ & $\mathrm{R} \$$ & 0,00 & $\mathrm{R} \$$ & 799,00 & $\mathrm{R} \$$ & - \\
\hline Despesas com transporte & $\mathrm{R} \$$ & $4.910,00$ & $\mathrm{R} \$$ & 0,01 ' & $\mathrm{R} \$$ & $7.340,00$ & $\mathrm{R} \$$ & 0,01 & $\mathrm{R} \$$ & $2.430,00$ & $\mathrm{R} \$$ & 0,01 \\
\hline Energia Eletrica & $\mathrm{R} \$$ & $11.388,00$ & $\mathrm{R} \$$ & 0,01 & $\mathrm{R} \$$ & $19.687,00$ & $\mathrm{R} \$$ & 0,03 & $\mathrm{R} \$$ & $8.299,00$ & $\mathrm{R} \$$ & 0,02 \\
\hline Telefone e Internet & $\mathrm{R} \$$ & - & $\mathrm{R} \$$ & - & $\mathrm{R} \$$ & $3.910,00$ & $\mathrm{R} \$$ & 0,01 & $\mathrm{R} \$$ & $3.910,00$ & $\mathrm{R} \$$ & 0,01 \\
\hline Fretes Diversos & $\mathrm{R} \$$ & - & $\mathrm{R} \$$ & - & $\mathrm{R} \$$ & $4.120,00$ & $\mathrm{R} \$$ & 0,01 & $\mathrm{R} \$$ & $4.120,00$ & $\mathrm{R} \$$ & 0,01 \\
\hline Viagens e Estadias & $\mathrm{R} \$$ & $3.112,00$ & $\mathrm{R} \$$ & 0,00 & $\mathrm{R} \$$ & $7.997,00$ & $\mathrm{R} \$$ & 0,01 & $\mathrm{R} \$$ & $4.885,00$ & $\mathrm{R} \$$ & 0,01 \\
\hline Certificações & $\mathrm{R} \$$ & - & $\mathrm{R} \$$ & - & $\mathrm{R} \$$ & $17.148,00$ & $\mathrm{R} \$$ & 0,03 & $\mathrm{R} \$$ & $17.148,00$ & $\mathrm{R} \$$ & 0,03 \\
\hline Depreciação & $\mathrm{R} \$$ & $109.842,00$ & $\mathrm{R} \$$ & 0,13 & $\mathrm{R} \$$ & $112.546,00$ & $\mathrm{R} \$$ & 0,19 & $\mathrm{R} \$$ & $2.704,00$ & $\mathrm{R} \$$ & 0,06 \\
\hline Custo Total & $\mathrm{R} \$$ & $860.551,00$ & & & $\mathrm{R} \$$ & $602.863,00$ & & & & & & \\
\hline
\end{tabular}

Os custos podem ser classificados, dentre outros, como custos fixos ou variáveis, de acordo com sua finalidade. Os custos variáveis ocorrem de acordo com o volume da produção, os demais permanecem fixos.

Conforme tabela 2, são classificados como custos variáveis o custo de animais produzidos, GTA de transferência, sal mineral, vermífugos, outros produtos veterinários, brincos e rastreabilidade, mortes, vacinas, frete de animais e rações do confinamento. Os custos fixos são, outros custos diversos / desenvolvimento social, manutenção de equipamentos e ferramentas, pequenas ferramentas, seguro de vida, uniformes em geral, taxas diversas INCRA, material de limpeza, curso de formação de profissional, EPI material de segurança, material de escritório, INSS , INSS sobre autônomo combustíveis e lubrificantes, transporte de funcionários, manutenção de rede elétrica, energia elétrica, manutenção de rede telefônica e internet, telefone e internet, fretes diversos, manutenção de veículos, viagens e estadias, FGTS, assistência medica e odontológica, $13^{\circ}$ salario, férias, manutenção de pastagem, consultoria técnica, alimentação, certificações, manutenção de cercas, serviços prestados por terceiros, manutenção de tratores e implementos, manutenção de construção civil, salários, manutenção de instalações e infraestrutura e depreciação. 
Custos de produção de gado bovino em regime de confinamento: analise do metodo de custeio por absorção em uma propriedade rural em Tangara da Serra-MT

Monica Aparecida Burgos Alexandre Pinto

Cleiton Franco

Dentre os custos variáveis, os mais relevantes em termos de decisão de produção por unidade adicional são o custo de animais produzidos que em 2011 foram $\mathrm{R} \$ 9.600 .000,00$ e em 2012 foram $\mathrm{R} \$ 8.800 .000,00$, o frete de animais em 2011 foram $\mathrm{R} \$ 345.721,00$ e em 2012 foram $\mathrm{R} \$ 461.874,00$ e rações do confinamento em 2011 foram $\mathrm{R} \$ 5.783 .748,00$ e em 2012 foram $\mathrm{R} \$ 5.255 .710,00$. Dentre os custos fixos, os mais relevantes são manutenção de instalações e infraestrutura em 2011 com $\mathrm{R} \$ 204.124,00$ e em 2012 com $\mathrm{R} \$ 98.284,00$; manutenção de tratores e implementos com R\$247.392,00 em 2011 e em 2012 com $\mathrm{R} \$ 39.424,00$ e manutenção de equipamentos e ferramentas com $\mathrm{R} \$ 9.398,00$ em 2011 e em 2012 com $\mathrm{R} \$ 29.466,00$.

\subsection{Análise de rentabilidade}

Tabela 3 - Margem de contribuição através da utilização dos custos fixos e variáveis

\begin{tabular}{|c|c|c|c|c|c|c|c|}
\hline \multirow[b]{3}{*}{ PV } & \multirow{2}{*}{\multicolumn{2}{|c|}{$\begin{array}{c}\text { PERIODO } \\
2011\end{array}$}} & \multirow{2}{*}{\multicolumn{2}{|c|}{$\begin{array}{c}\text { PERIODO } \\
2012\end{array}$}} & \multicolumn{3}{|c|}{ VARIAÇÃO } \\
\hline & & & & & & $\mathrm{R} \$$ & $\%$ \\
\hline & $\mathrm{R} \$$ & $1.629,54$ & $\mathrm{R} \$$ & $1.583,64$ & $\mathrm{R} \$$ & 45,90 & $-0,97 \%$ \\
\hline$(-) C V+D V$ & $\mathrm{R} \$$ & $1.316,73$ & $\mathrm{R} \$$ & $1.327,90$ & $\mathrm{R} \$$ & 11,17 & $-1,0 \%$ \\
\hline$(=)$ Mcun & $\mathrm{R} \$$ & 312,81 & $\mathrm{R} \$$ & 255,74 & $\mathrm{R} \$$ & 57,07 & $-0,81 \%$ \\
\hline$(=) \mathrm{MC} \mathrm{ttl}$ & $\mathrm{R} \$$ & $3.753 .720,00$ & $\mathrm{R} \$$ & $2.813 .140,00$ & $\mathrm{R} \$$ & $940.580,00$ & $-0,74 \%$ \\
\hline
\end{tabular}

Conforme tabela 3 a margem de contribuição de cada cabeça representa em relação ao custo fixo total em 2011 é $\mathrm{R} \$ 3.753 .720,00$ ou $\mathrm{R} \$ 312,81$ por cabeça. Já em 2012 este resultado é de $\mathrm{R} \$ 2.813 .140,00$ ou $\mathrm{R} \$ 255,74$ por cabeça. Esta diferença de valores se dá devido à quantidade de cabeças produzidas em 2011 (12.000 cabeças) ser maior que em 2012 (11.000 cabeças).

Tabela 4 - Ponto de equilíbrio em quantidades considerando os custos fixos e variáveis para os períodos de 2011 e 2012.

\begin{tabular}{lrrrr}
\hline & PERIODO & \multicolumn{2}{c}{ PERIODO } & \multicolumn{2}{c}{ VARIAÇÃO } \\
& $2.011,00$ & $2.012,00$ & \multicolumn{1}{c}{ R \$ } & $\%$ \\
CUSTOS E DESPESAS FIXOS & $831.251,00$ & $622.931,00$ & $208.320,00-$ & 0,25 \\
( / ) MARGEM DE CONTRIBUIÇÃO unit. & 312,81 & 255,74 & $57,07-$ & 0,18 \\
(=)PONTO DE EQUILIBRIO & $2.657,37$ & $2.435,80$ & $221,57-$ & 0,08 \\
\hline
\end{tabular}

A tabela 4 traz o ponto de equilíbrio em quantidade que para alcançar este ponto em 2011 foram necessários produzir 2.657 cabeças. Já em 2012 foram necessários 2.436 cabeças, que é o ponto onde a empresa não terá prejuízo, porém ainda não obteve lucro.

Tabela 5- Ponto de equilíbrio em valores considerando os custos fixos e variáveis para os períodos de 2011 e 2012. 
Custos de produção de gado bovino em regime de confinamento: analise do metodo de custeio por absorção em uma propriedade rural em Tangara da Serra-MT Monica Aparecida Burgos Alexandre Pinto

Cleiton Franco

\begin{tabular}{|c|c|c|c|c|c|c|c|}
\hline \multirow[b]{3}{*}{ CUSTOS E DESPESAS FIXOS } & \multirow{2}{*}{\multicolumn{2}{|c|}{$\begin{array}{l}\text { PERIODO } \\
2011\end{array}$}} & \multirow{2}{*}{\multicolumn{2}{|c|}{$\begin{array}{c}\text { PERIODO } \\
2012\end{array}$}} & \multicolumn{3}{|c|}{ VARIAÇÃO } \\
\hline & & & & & \multicolumn{2}{|c|}{$\mathrm{R} \$$} & \multirow{2}{*}{$\begin{array}{c}\% \\
-3,0 \%\end{array}$} \\
\hline & $\mathrm{R} \$$ & $1.629,54$ & $\mathrm{R} \$$ & $1.583,64$ & $\mathrm{R} \$$ & 45,90 & \\
\hline ( / ) CUSTOS E DESPESAS VARIA VEIS unit. & $\mathrm{R} \$$ & $1.316,73$ & $\mathrm{R} \$$ & $1.327,90$ & $R \$$ & 11,17 & $-0,85 \%$ \\
\hline ( / ) PREÇO DE VENDA unit. & $\mathrm{R} \$$ & 312,81 & $\mathrm{R} \$$ & 255,74 & $\mathrm{R} \$$ & 57,07 & $-18 \%$ \\
\hline (=)PONTO DE EQUILIBRIO & $\mathrm{R} \$$ & $1.026 .235,80$ & $\mathrm{R} \$ 74$ & $1.584,52$ & $R \$ 2$ & $4.651,28$ & $-72 \%$ \\
\hline
\end{tabular}

O ponto de equilíbrio em valores representado na tabela 5 traz o seguinte resultado, em 2011 foi necessário $\mathrm{R} \$ 1.026 .235,8$ para alcançar o ponto de equilíbrio, que em 2012 foi alcançado com $\mathrm{R} \$ 741.584,52$.

Outros autores que fizeram a análise da rentabilidade foram Klein e Staudt (2009) que encontraram, na propriedade estudada, em seus resultados como sendo o maior custo no confinamento de gado de corte a aquisição de animais representando $62,90 \%$ do total dos gastos, seguida pela a ração que representa 28,72\%. Também na mesma linha de analise Lopes e Magalhães (2005) com um custo de aquisição de animais representando 66,57\% dos custos totais e a alimentação representando 30,25\% do custo total. Ainda na mesma linha de estudo vem kubiak (2008), com os custos da aquisição de animais responsável por 58,23\% do custo total, seguido da alimentação que representa por $38,70 \%$ do custo total. A fazenda em estudo teve seus percentuais de custo de compra de animais em 2011 representando 57,71\% e em 2012, 57,78\% se aproximando mais do resultado do autor kubiak (2008). O segundo maior custo foi também com a alimentação em 2011 foi de 34,77\% e em 2012 foi de 34,5\% do custo total ficando entre os autores Lopes e Magalhães (2005) e Kubiak (2008).

Conforme dados do custo na bovinocultura divulgado pelo IMEA para o primeiro semestre, os custos do confinamento deveriam girar em torno de R \$ 78,43 por @ em 2011 e R\$78,13 por@em 2012, Já em dezembro de 2011 foi divulgado a media do preço da @ do boi gordo que ficou cotada a R \$90,53 por @ e em novembro de 2012 a R\$ 87,98 por@

De acordo com boletim do IMEA divulgado em 02 de dezembro de 2011, a media do preço da @ do boi gordo, nesta semana ficou cotada a $\mathrm{R} \$ 90,53$ por @ . Na fazenda em estudo a @ do boi gordo custou R $\$ 77,00$ por @ e considerando que o boi deve pesar $18 @$ no momento de ir para o abate, podemos afirmar que foi pago por cada boi gordo $\mathrm{R} \$ 1.629,54$, como a fazenda teve um custo de $\mathrm{R} \$ 1.386,00$ por animal o seu lucro liquido foi de $\mathrm{R} \$ 243,54$ cada boi gordo. Naquele ano, foram para os currais 12.000 cabeças, então, o lucro total ficou em R \$ 2.922.480,00,

Em 30 de novembro de 2012, saiu um boletim do IMEA divulgando a media do preço da @ do boi gordo, que nos últimos cinco dias, ficaram cotada a $\mathrm{R} \$ 87,98$ por @. Na fazenda 
Custos de produção de gado bovino em regime de confinamento: analise do metodo de custeio por absorção em uma propriedade rural em Tangara da Serra-MT

Monica Aparecida Burgos Alexandre Pinto

Cleiton Franco

em estudo a @ do boi gordo custou R\$77,92 por @; portanto, levando-se em consideração que o boi deve pesar 18@ no momento de ir para o abate, podemos afirmar que foi pago por cada boi gordo $\mathrm{R} \$ 1.583,64$, como a fazenda teve um custo total de $\mathrm{R} \$ 1.384,53$ por animal o seu lucro liquido foi de $\mathrm{R} \$ 119,11$ por cabeça. Naquele ano, foram para os currais 11.000 cabeças, então, o lucro total ficou em R $\$ 2.922 .459,00$.

\section{CONSIDERAÇÕES FINAIS}

A fazenda vem desenvolvendo a atividade de confinamento de forma satisfatória, garantindo a sua viabilidade econômica, confirmando assim as expectativas de continuidade da atividade em outros períodos. Os itens que provocaram maior impacto no custo total foi à aquisição de animais, seguido pela alimentação durante o período de engorda.

O estudo alcançou o seu objetivo de analisar os custos de produção na terminação do gado de corte em regime de confinamento, através do emprego do método de custeio. A metodologia utilizada para a presente pesquisa envolveu estudo de caso de uma propriedade rural, localizada no município de Tangará da Serra-MT. Todos os custos e dados apresentados foram fornecidos pela fazenda através de pesquisa documental, e exposto pela autora de forma mais didática possível.

Deve-se lembrar de que a viabilidade foi possível em grande parte, devido ao bom preço de aquisição, média de $\mathrm{R} \$ 72,72 / @$, e em contra partida bom preço recebidos na venda, média de R\$97,94/@, dos animais e também do custo da alimentação, que tem a composição da ração elaborada na própria fazenda.

Recomendam-se outros trabalhos que visem aprimorar a área de custos em confinamento de gado, para que estes possam servir como base para outras fazendas de gado confinado.

\section{AGRADECIMENTOS}

Ao professor e orientador Cleiton Franco pela atenção, dedicação e pelas valiosas contribuições dadas a esse artigo. Bem como a banca examinadora por ter também emprestado sua contribuição. Especialmente aos meus pais, Rafael e Neide, por terem me apoiado durante essa trajetória, com muita paciência, compreensão e dedicação. À fazenda, que abriu suas portas a esta pesquisa acreditando na seriedade deste trabalho e ao funcionário que me disponibilizou sua paciência e os dados necessários para que esta pesquisa seguisse em frente. Enfim, agradeço a todos aqueles que estiveram presentes, direta ou indiretamente, durante esse período de crescimento pessoal. 


\section{REFERÊNCIAS}

AGUIAR, Adilson de Paula Almeida; RESENDE, Juliano Ricardo; Pecuária de Corte: Custos de Produção e Análise Econômica, $1^{\circ}$ Ed. Editora Aprenda Fácil, ViçosaMG, 2010

Autor: Fonte: Diário de Cuiabá, Mato Grosso não deve se concretizar Extraído de: primeirahora.agronegocios, Junho $\quad$ 03, 2013 disponivel: http://www.ecofinancas.com/noticias/estimativa-bovinos-confinados-mato-grosso-deveconcretizar acessado em 23/09/2013 as 22:04 hrs

BEUREN, Ilse Maria; LONGARAY, André Andrade; RAUPP, Fabiano Maury; SOUSA, Marco Aurélio Batista de. Como elaborar trabalhos monográficos em contabilidade: teoria e prática. $3^{\mathrm{a}}$ ed., atual. São Paulo, SP: Atlas, 2006.

CASTURINO, Vandersezar; Stanghilin, Andriélli Silva dos Santos, Sistema de Controle de Custos no Confinamento de Bovinos em Estudo de Caso na Região Medio-Norte-MatoGrossense. IV Ciclo de palestras em ciências sociais aplicadas, Oportunidades e desafios nas ciências sociais aplicadas: relações interorganizacionais, trabalho e renda. Sinop, MT, Brasil, 18 a 2 de outubro de 2010

CREPALDI, Silvio Aparecido. Contabilidade rural uma abordagem Decisorial/ $3^{\mathrm{a}}$ edição atualizada de acordo com alei $\mathrm{n}^{\mathrm{a}}$ 11.638/07 e 11.941/09. Editora atlas 2005;

DA SILVA, Danilo Oliveira; PESTANA, Eduardo; De Souza; KANEKO, Helcio Shin-Iti; Gestão de custos com ênfase em confinamento bovino. (Trabalho de conclusão de curso). Centro Universitário Católico Salesiano Auxilium, LINS -SP 2008.

DUTRA, René gomes; Custos: Uma Abordagem Prática, $4^{\circ}$ Edição Revisada, São Paulo, Ed. Atlas S.A. 1995

FARIA, V.P. desempenho zootécnico-econômico: como avaliar. Balde Branco. São Paulo , n486, p26-29. Abril de 2005.

HANSEN, Don R; MOWEN, Mariane M.; Tradução: Robert Brian Taylor, Revisão Técnica: Elias Pereira; São Paulo; Editora Cengage Learning, 2001. 
Instituto Matogrossense de Economia Agropecuária (IMEA). Caracterização da bovinocultura no Estado de Mato grosso, disponível em: <http://www.imea.com.br/ $\geq$ acessado em 23/09/2013 às 21h57min.

Instituto Matogrossense de Economia Agropecuária (IMEA). $2^{\circ}$ Levantamento das intenções de confinamento em 2011, publicado dia 28 de julho de 2011, disponível em: http://www.imea.com.br/upload/pdf/arquivos/11_07_28_Confinamento_julho_2011.pdf

Instituto Matogrossense de Economia Agropecuária (IMEA). $\mathbf{2}^{\circ}$ Levantamento das intenções de confinamento em 2012, publicado dia 14 de agosto de 2012, disponível em: http://www.imea.com.br/upload/pdf/arquivos/2012_08_14_Confinamento_julho_2012.pdf acessado 15:52 dia 28/09/2013

IBGE, Produção Animal no $1^{\circ}$ Trimestre de 2013, disponível em: http://www.ibge.gov.br/home/estatistica/indicadores/agropecuaria/producaoagropecuaria/abat e-leite-couro-ovos_201301comentarios.pdf acessado em 23/09/2013 , 21:34

IUDICIBUS, Sérgio de; Teoria da Contabilidade; $6^{\circ}$ edição, São Paulo; Editora Atlas; 2000

KLEIN, Cristian Joé; Staudt, Tarcísio Analise da rentabilidade de confinamento de gado a partir da utilização de um método de custeio.

KUBIAK, Karine Ibañez, Proposta de um Sistema de Custos para uma fazenda de confinamento de gado. (Monografia). UFSC - Universidade Federal de Santa Catarina. Florianópolis, 2006. É da internet não é? Ou você foi à SC?

LOPES, Marcos Aurelio; Magalhães, Pires Gustavo; Rentablidade na terminação de bovinos de corte em confinamento: um estudo de caso em 2003 na região oeste de minas gerais. Ciênc. agrotec., Lavras, v. 29, n. 5, p. 1039-1044, set./out., 2005

MARCONI, Maria de Andrade; LAKATOS, Eva Maria, Metodologia Cientifica (Ciência do conhecimento cientifico, métodos científicos, teoria, hipóteses e variáveis, metodologia jurídica) $5^{a}$ edição revista e ampliada. São Paulo editora Atlas S.A.- 1991

MARION, José Carlos, Contabilidade Rural. 4ª ed. São Paulo, SP: Atlas, 1996.

MARION, Jose Carlos, Contabilidade da Pecuária, $8^{a}$ edição, revisão técnica Sonia Segatti, São Paulo ed. Atlas 2007. Ver como coloca vários trabalhos de um mesmo autor, geralmente se faz um traço de 2 a $3 \mathrm{~cm}$. 
Custos de produção de gado bovino em regime de confinamento: analise do metodo de custeio por absorção em uma propriedade rural em Tangara da Serra-MT

Monica Aparecida Burgos Alexandre Pinto

Cleiton Franco

MARION, Jose Carlos, Contabilidade Agrícola, Contabilidade Pecuária, Imposto de renda- Pessoa Jurídica, 12a edição Atualizada conforme lei № 11.638/07 e 11.941/09 São Paulo ed. Atlas SA 2010.

MARION, Jose Carlos, SEGATTI, Sonia, Contabilidade da Pecuária, $9^{\circ}$ edição atualizada pelas leis $\mathrm{N}^{\circ}$ s 11.638/07 e 11.941/09 ; São Paulo Editora Atlas, 2010,

MARTINS, Eliseu, Contabilidade de Custos, São Paulo, Editora atlas S.A- 1996.

MEGLIORINI, Evandir, Custos Analise e Gestão, $2^{\text {a }}$ edição revista e ampliada, São Paulo editora Pearson Prentice Hall, 2007.

Ministério da Agricultura, Pecuária e Abastecimento, reportagem disponível em:

http://www.agricultura.gov.br/portal/page/portal/Internet-MAPA/pagina-

inicial/animal/especies/ acessado em 23/09/2013 as 21:43 hrs

MOREIRA, S A; Thomé K. M; Ferreira, P. da S; Botelho Filho, F. B. Análise econômica da terminação de gado de corte em confinamento dentro da dinâmica de uma propriedade agrícola. Custos e Agronegócio online - v. 5, n. 3, p. 132 - 152 - Set/Dez 2009.

RIBEIRO, Osni Moura, Contabilidade de custos (Alterações trazidas pela lei n.11.638, de 28 de dezembro de 2007), Editora Saraiva, 2009

Secretaria de Estado de planejamento, Pecuária: criação de gado e ovelhas são destaque no Estado. Disponível em:

http://www.mteseusmunicipios.com.br/NG/conteudo.php?sid=63\&cid=2423

SIPP, Alisiane Mara; Analise de viabilidade econômica de Bovinos de Corte em uma propriedade rural, Trabalho de Conclusão de Curso, Departamento de Ciências e Engenharia da Universidade Tecnológica Federal do Paraná - UTFPR - Campus de Pato Branco. Orientador: Prof.M.Sc. Antônio Cecílio Silvério PATO BRANCO 2011

SOUZA, Profa. Cecília de F.; TINOCO, Profa. Ilda de F. F.;SARTOR, Prof. Valmir, Universidade Federal de Viçosa Centro de Ciências Agrárias Departamento de Engenharia Agrícola Área de Construções Rurais e Ambiência Informações básicas para projetos de construções rurais, Viçosa Minas Gerais 2003 (Unidade 2) Bovinos de Corte disponível em: http://www.ufv.br/dea/ambiagro/arquivos/instala\%C3\%A7\%C3\%B5esgadocorte.pdf acesso em: 21/07/2013 18:00hrs. 
Custos de produção de gado bovino em regime de confinamento: analise do metodo de custeio por absorção em uma propriedade rural em Tangara da Serra-MT

Monica Aparecida Burgos Alexandre Pinto Cleiton Franco

WERNKE, Rodney /Gestão de Custos Uma Abordagem Pratica / São Paulo Editora Atlas S.A-2001.

ZILIOTTO, Maiara Ricci; Silveira, Cheila; CAMARGO, Maria Emilia, DA MOTTA, Marta Elisete Ventura; FILHO, Walter Priesnitz, Comparação do Custo de Produção de Bovinocultura de Corte: Pasto versus Confinamento, VII SEGeT-Simpósio de Excelência em Gestão e Tecnologia - 2010 